\title{
Viral Hepatitis A and B as Differential in Children Presenting with Acute Glomerulonephritis
}

\author{
Parul Bhardwaj ${ }^{1}$, Anju Bala ${ }^{2}$, Parvinder Singh $^{3}$ \\ ${ }^{1}$ MD Internal Medicine, Civil Hospital Dehra (H.P.) \\ ${ }^{2}$ MD Pediatrics, Civil Hospital Nadaun (H.P.) \\ ${ }^{3}$ Senior Resident Pediatrics, DRKGMC Hamirpur (H.P.) \\ Corresponding Author: Anju Bala
}

\begin{abstract}
Hepatitis A and B presenting as acute glomerulonephritis is rare in pediatric age group. In children it is necessary to recognize glomerulonephritis early in the course of disease so as to prevent long term morbidity. Cases described in this report indicate that children presenting with acute glomerulonephritis must be investigated for viral hepatitis.
\end{abstract}

Keywords: Glomerulonephritis, Hepatitis A, Hepatitis B

\section{BACKGROUND}

In pediatric population the diseases commonly manifesting as glomerulonephritis are post streptococcal glomerulonephritis, IgA nephropathy and membranoproliferative glomerulonephritis ${ }^{1}$. Hepatitis A and hepatitis B presenting as acute glomerulonephritis is rare in pediatric age group. Although hepatitis B through its immune mediated mechanisms can cause membranoproliferative and membranous glomerulonephritis. Mostly hepatitis A involves liver but there are few case reports which describe its extrahepatic manifestations.

Here we are reporting two pediatric cases where acute glomerulonephritis was the first presentation of patients suffering from hepatitis A and hepatitis B.

\section{CASE REPORT \\ Case I}

A nine years old male child presented with one day history of pain lower abdomen, vomiting with red colored urine. There was no history of fever, jaundice, periorbital puffiness, burning micturition, urgency and hesitancy while passing urine. There was no preceding history suggesting of viral illness, pyoderma and drug intake. No history of similar illness in past. Family history was insignificant. On examination child was conscious and well oriented to time place and person. He was hemodynamically stable with icterus present on general physical examination. On systemic examination nothing significant found. On laboratory investigations complete blood count, serum electrolytes and renal function tests were normal. Liver function tests were deranged as total serum bilirubin of $4.30 \mathrm{mg} / \mathrm{dl}$ with $2.54 \mathrm{mg} / \mathrm{dl}$ direct component. Alanine aminotransferase and aspartate aminotransferase were significantly raised with mild derangement in coagulation profile. Urine routine and microscopic examination was suggestive of glomerular origin of hematuria [Table-1]. Ultrasound abdomen was suggestive of mild ascites with normal liver and renal echotexture. With this history, examination and investigations possibility of acuteglomerulonephritis secondary to hepatitis was kept. Patient was started on injection vit $\mathrm{K}$, ursodeoxycholic acid and lactulose after bowel clearance with polyethylene glycol. 
Patient improved after symptomatic treatment and discharged on day 3 of admission. After 48 hours on follow up patient came with pending investigations. Hepatitis A $\operatorname{IgM}$ was reactive with normal C3 level and negative Antistreptolysin O titer. On subsequent visits there was no hypertension, proteinuria and hematuria on urine examination, although patient is still under follow up.

\section{Case II}

Seventeen years old female adolescent presented with three days history of vomiting, fever, dyspnea while walking, red colored urine along with decreased urine output for two days. There was no history of periorbital puffiness and pedal edema and jaundice. In past history there was nothing significant with normal dietary intake and physical activity before the onset of illness. On examination patient was conscious but drowsy and lethargic. On general physical examination icterus was present and blood pressure $(148 / 90 \mathrm{mmHg})$ was in hypertensive range. There was mild hepatomegaly on per abdomen examination. On central nervous system examination cranial nerves were normal with deep tendon reflexes $2+$ and bilateral plantar reflex were down going. On investigations complete blood count was suggestive of anemia and leukocytosis along with neutrophilic predominance. Liver function tests, coagulation profile and renal function tests were deranged significantly [Table-1]. Urine routine and microscopic examination revealed numerous dysmorphic RBCs and $2+$ proteinuria. Ultrasonography was suggestive of raised renal and liver echotexture. On further investigation hepatitis B surface antigen was reactive. On the basis of history, examination and laboratory investigations provisional diagnosis of acute glomerulonephritis secondary to hepatitis $\mathrm{B}$ with hepatic encephalopathy stage II with coagulopathy was kept. Patient was started on IV fluids, injection vit $\mathrm{K}$, lactulose and rifaximin with feeding tube. After 6 hours of hospitalization urine output was $50 \mathrm{ml}$ which suggest significant renal involvement. As we were managing the patient at secondary health care center so we refer the patient to higher center for renal biopsy and renal replacement therapy. At higher center patient was kept in ICU and started on dialysis. She died on day 2 of admission despite all these measures.

\section{Investigations:}

\begin{tabular}{|c|c|c|c|}
\hline & Case I & & Case II \\
\hline Dated & At admission & Day 5 of admission & At admission \\
\hline $\mathrm{Hb}(\mathrm{gm} / \mathrm{dl})$ & 12.50 & 12.30 & 8.8 \\
\hline TLC (per cmm) & 7200 & 6800 & 25000 \\
\hline Neutrophil/lymphocytes(\%) & $51 / 44$ & $49 / 15$ & $86.9 / 9.8$ \\
\hline Platelets (per cmm) & 152000 & 163000 & 206000 \\
\hline Total Bilirubin(mg/dl) & 4.30 & 1.21 & 5.0 \\
\hline $\operatorname{Direct}(\mathrm{mg} / \mathrm{dl})$ & 2.54 & 0.36 & 2.0 \\
\hline Indirect bilirubin(mg/dl) & 1.84 & 0.85 & 3.0 \\
\hline SGOT/SGPT(IU/L) & $2804 / 3038$ & $164 / 526$ & $458 / 650$ \\
\hline Alkaline phosphatase(mg/L) & 390 & 301 & 184 \\
\hline Total Serum Protein(gm/dl) & 6.90 & 6.50 & 5.6 \\
\hline Serum Albumin $(\mathrm{gm} / \mathrm{dl})$ & 4.50 & 4.30 & 3.2 \\
\hline Serum globulin(gm/dl) & 2.40 & 2.20 & 2.4 \\
\hline PT/INR/APTT & 19/1.46/39.9 & $18 / 1.33 / 35$ & $24 / 2$ \\
\hline Blood urea(mg/dl) & 20 & - & 92 \\
\hline Serum creatinine $(\mathrm{mg} / \mathrm{dl})$ & 0.8 & - & 3.2 \\
\hline Hepatitis A IgM (IU/ml) & $\mathbf{1 5 . 2 6}($ Normal<0.08) & - & Non- reactive \\
\hline Hepatitis E IgM & Negative & - & Negative \\
\hline Hepatitis B surface antigen & Non- reactive & - & Reactive \\
\hline Hepatitis $\mathrm{C}$ antibodies & Non -reactive & - & Non-reactive \\
\hline Urine routine and microscopy examination & $\begin{array}{l}\text { Full of RBCs (dysmorphic) } \\
\text { No proteins }\end{array}$ & Normal & Full of RBCs(dysmorphic) \\
\hline
\end{tabular}




\section{DISCUSSION}

Hepatitis A is usually self-limiting disease and lead to fulminant hepatic failure in $<0.5 \%$ cases in pediatric population ${ }^{3}$. Hepatitis A virus can cause acute glomerulonephritis, interstitial nephritis, IgA nephropathy and cryoglobulinaemic vasculitis $^{2}$. The exact mechanism is not known, it is probably immune complex mediated as seen in hepatitis B. During liver cell dysfunction circulating immune complexes detoxification got impaired leading to tissue deposition and damage to glomeruli ${ }^{4}$. The virus itself may initiate glomerular injury as evidenced by demonstration of tubule-reticular viral particles in electron microscopy ${ }^{4}$. Other possible mechanisms are prerenal factors (like circulatory insufficiency and impaired renal blood flow, nephrotoxic substances etc.), endotoxaemia and endotoxin-induced disseminated intravascular coagulation ${ }^{5}$. Despite very few cases reporting, mesangioproliferative is the most common type of glomerulonephritis seen in histopathology in children ${ }^{4}$. It is characterized by electrondense and immunofluorescent deposits, especially marked IgM and $\mathrm{C} 3$, and hypercellularity with mesangeal proliferation ${ }^{4}$. Hepatitis B virus (HBV) is a member of the family hepadnaviridae that is endemic in many areas across the world. HBV causes transient and/or persistent infection in the liver after its incorporation, relying on hepatocytes to replicate itself. HBV may also infect extrahepatic tissue such as the bile duct, the pancreas, the lymphoid system, and the kidneys ${ }^{7}$. The most common type of HBV associated glomerulonephritis is membranous nephropathy. While a significant reduction in prevalence of HBsAg carriers and HBV associated membranous nephropathy in children after extensive $\mathrm{HBV}$ immunization in recent years has been reported, HBV-GN remains a significant problem ${ }^{6}$. Pathologically, HBV-PIGN exhibited the typical changes associated with acute glomerulonephritis, including glomerular endocapillary proliferation and deposition of immunoglobulins, and deposition of complements $\mathrm{C} 3$ and $\mathrm{C}_{4}^{8}$. The abovedescribed cases indicate that history, clinical examination and simple laboratory investigation and can lead us to diagnosis of glomerulonephritis and associated hepatitis. By early diagnosis and management of renal disease in hepatitis the quality of life can be significantly improved in children.

\section{CONCLUSION}

Hepatitis A has a self-limiting course. Glomerulonephritis had found to be one of the complications of hepatitis A that can lead to renal damage, although the treatment is symptomatic and outcome is good. This necessitates early recognition of signs and symptoms. Glomerulonephritis secondary to hepatitis B is well known entity that can lead to permanent renal damage. Presenting with signs and symptoms of acute glomerulonephritis in a case of hepatitis $\mathrm{A}$ and $\mathrm{B}$ is quite rare. Vaccination has significantly decreased the cases of hepatitis B and further glomerulonephritis. We can conclude that any child who presents with nephritic syndrome should be investigated for viral hepatitis A along with hepatitis B and C. These basic laboratory investigations which are easily available even below the level of tertiary health care institute can help in early diagnosis and management leading to better outcome.

\section{Declaration of patient consent:}

The authors certify that we have obtained all appropriate patient consent on forms regarding clinical information to be reported in the journal.

\section{Financial Support and Sponsorship: Nil.}

Conflicts of Interest: There are no conflicts of interest.

Source of Funding: None 
Parul Bhardwaj et.al. Viral hepatitis $A$ and $B$ as differential in children presenting with acute glomerulonephritis.

\section{REFERENCES}

1. Flores F. Nelson textbook of pediatrics. Philadelphia, PA; Elsevier: 2019

2. Vaboe AL, Leh S, Forslund T. Interstitial nephritis, acute renal failure in a patient with non-fulminant hepatitis A infection. Clin Nephrol 2002; 57: 149-53.

3. Jensen M, Balistreri W. Nelson textbook of pediatrics. Philadelphia, PA; Elsevier: 2019

4. Zikos D, Grewal KS, Craig K, Cheng JC, Peterson DR, Fisher KA. Nephrotic syndrome and acute renal failure associated with hepatitis A virus infection. Am J Gastroenterol 1995; 90: 295-8.

5. Lin CC, Chang $\mathrm{CH}$, Lee SH, Chiang SS, Yang AH. Acute renal failure in non fulminant hepatitis A. Nephrol Dial Transplant 1996; 11: 2061-6

6. Liao MT, Chang MH, Lin FG, Tsai IJ, Chang YW, Tsau YK. Universal hepatitis B vaccination reduces childhood hepatitis $\mathrm{B}$ virus-associated membranous nephropathy. Pediatrics. 2011. September;128(3):e600-4. 10.1542/peds.2010-3137.

7. Seeger C, William S. Hepatitis B Virus Biology. Mason Microbiol Mol Biol Rev. 2000; 64(1): 51-68.

8. Zhang Y, Li J, Peng W, et al. HBVAssociated Postinfectious Acute Glomerulonephritis: A Report of 10 Cases. PLoS One. 2016;11(8): e0160626.

How to cite this article: Bhardwaj P, Bala A, Singh P. Viral hepatitis A and B as differential in children presenting with acute glomerulonephritis. International Journal of Science \& Healthcare Research. 2021; 6(3): 154-157. DOI: https://doi.org/10.52403/ijshr. 20210725 